Los tumores testiculares representan el 1-2\% de todas las neoplasias del sexo masculino y el $4 \%$ de las neoplasias urogenitales; siendo más comunes en la raza blanca (5/1), entre los 20-35 años ${ }^{5}$ y localizándose con más frecuencia en el testículo derecho $(52,3 \%)^{6}$.

La criptorquidia y el antecedente de tumor en el testículo contralateral son los factores de riesgo más significativos ${ }^{7}$. En testículos criptorquídeos, la incidencia de cáncer testicular se estima entre 3 y 48 veces mayor a la de la población general. Aproximadamente un $10 \%$ de todos los tumores testiculares aparecen sobre un testículo no descendido.

De los testículos no palpables, solo en el $20 \%$ de los casos están ausentes; el resto se encuentra en el abdomen o en el canal inguinal, presentando los primeros una tasa más alta de malignización (30\%); las altas temperaturas de estos sitios serían las responsables. En estos casos se debe localizar el testículo y, si el paciente es pospuberal, se recomienda la orquiectomía, especialmente por debajo de los 32 años. Algunos autores realizan una laparoscopia exploradora, que es diagnóstica y terapéutica a la vez en la mayoría de los $\operatorname{casos}^{8}$. A nuestro paciente se le realizó una laparoscopia exploratoria en su niñez que resultó negativa, por lo que se concluyó como una agenesia testicular.

La histopatología de los tumores de testículo no descendido en el adulto depende de la localización y la proporción de seminoma puro es del 93\% cuando se encuentra en situación abdominal, de un $63 \%$ si es inguinal y de un $28 \%$ en testes normotópicos ${ }^{9}$. El pronóstico dependerá del estadio inicial y de la histología del tumor ${ }^{8}$. Histológicamente presenta 3 subtipos: clásico, anaplásico y espermatocítico, de los cuales el primero es el más frecuente ${ }^{5}$.

En los últimos 20 años hay cada vez menos casos publicados, lo que se explicaría por el progresivo descenso de la incidencia de los tumores en testículos abdominales debido a la prevención ${ }^{8}$.

La existencia de testículos no descendidos en la población adulta es rara en los países desarrollados y en el nuestro debido a la práctica sistemática de orquidopexia electiva antes de los 2 años de vida y orquiectomía en pacientes pospúberes con testículos no descendidos. A pesar de estas medidas de prevención, aún se encuentran casos aislados de tumores testiculares abdominales en adultos.

B I B L I O G R A F Í A

1. Castejón Casado J, Jiménez Álvarez C, Alaminos Mingorance M, Valladares Mendías JC, Fernández Valadés R. Metaanálisis cáncer-criptorquidia. Cir Pediatr. 2000;13:92-6.

2. Kulkarni JN, Kamat MR. Tumor in undescended testis. J Surg Oncology. 1991;46:257-60.

3. Dirix LY, Wouters E, Van Nueten J, Van Eerdeweg W, Van Oosterom AT. Cryptorchidism and extragonadal germ cell tumor. Urol Int. 1995;55:44-5.

4. Rozanski TA, Bloom DA. The undescended testis. Theory and management. Urol Clin North Am. 1995;22:107-18.

5. Gil Sanz MJ, Cebrian CC, Villanueva Benedicto A, Liedana Torres JM, González Enguita C, Urruchi Fernández P, et al. Manejo diagnóstico y terapéutico de los tumores testiculares. Revisión de 15 años. Arch Esp Urol. 1991;44:417-23.

6. Adrianzón L, Bendezú G, Castro I, Cáceres S, Riva H, Tejada W. Cáncer de testículo. Revista Peruana de Radiología. 1998;2.

7. Abratt RP, Reddi VB, Sarembok LA. Testicular cancer and cryptorchidism. Br J Urol. 1992;70:656-9.

8. Cristián Palma C, Cristóbal B, Maccioni R. Seminoma de testículo abdominal en un paciente adulto: reporte de un caso. Actas Urol Esp. 2007;31:160-3.

9. Carmona Campos E, Regueiro Lopez JC, Prieto Castro R, Leva V, Moreno A, Requena T. Criptorquidia y cáncer testicular. Actas Urol Esp. 2000;24:49-51.

M. González Méndez, L. Solís Alfonso*, A. González López y M. Ramírez Simono

Hospital Universitario Dr. Carlos J. Finlay, Marianao, Ciudad de La Habana, Cuba

*Autor para correspondencia.

Correo electrónico: vicky@ida.cu (L. Solís Alfonso).

\title{
Metástasis mamaria como manifestación inicial de carcinoma de células renales
}

\section{Breast metastasis as initial presentation of renal cell carcinoma}

\section{Sr. Director:}

Presentamos el caso de una paciente mujer, de 62 años de edad, exfumadora desde hace 3 años de 20 paquetes/año, sin antecedentes de interés, salvo una neumonía por Legionella hace 3 años.
La paciente acudió a nuestro hospital por presentar una masa palpable, no dolorosa, en la mama izquierda. En la exploración física se apreció una masa móvil, firme, en el cuadrante superior externo de dicha mama.

La mamografía reveló dos lesiones en la mama izquierda: una que se correspondía con la lesión palpable, bien definida, con 


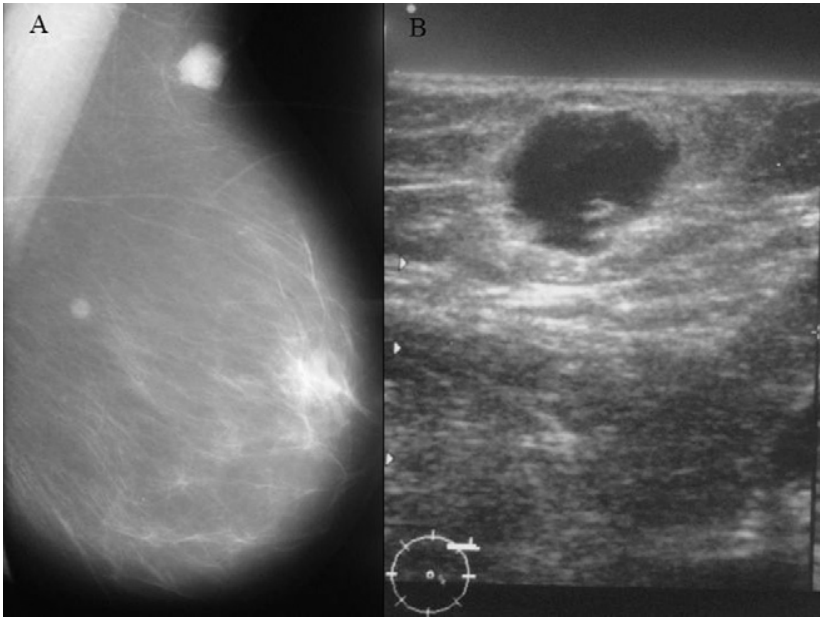

Figura 1 - A) Mamografía en proyección oblicua de la mama izquierda que no sólo revela la masa clínicamente palpable, sino también un pequeño nódulo en unión de cuadrantes externos. B) Ecografía de la mama izquierda en la que se aprecia lesión sólida hipoecogénica sin atenuación posterior.

márgenes ligeramente irregulares, y la segunda, subcentimétrica, bien definida, localizada en la unión de los cuadrantes externos. No se identificaron calcificaciones (fig. 1A). La ecografía mamaria mostró dos nódulos hipoecogénicos, homogéneos, sólidos, sin atenuación posterior $(1,78$ y $0,4 \mathrm{~cm})$. No se objetivaron adenopatías axilares en rango patológico (fig. 1B).

Se realizó una biopsia con aguja gruesa guiada por ecografía de ambas lesiones, revelando el examen histopatológico una tumoración bien delimitada, con necrosis central, altamente celular, atípica, con pleomorfismo nuclear y citoplasma anfófilo. Todos los estudios inmunohistoquímicos y marcadores sensibles para tumor primario de mama resultaron negativos. La vimentina fue intensamente positiva. Hubo hallazgos sugestivos de tumor metastático de células renales.

A continuación se realizó una tomografía computarizada, que demostró una masa de $10 \mathrm{~cm}$ en el polo superior del riñón derecho, con múltiples nódulos pulmonares metastásicos, implantes tumorales peritoneales y en tejido subcutáneo (fig. 2).

Se desestimó el tratamiento quirúrgico y la paciente fue derivada al Servicio de Oncología Médica para instaurar tratamiento sistémico (sunitinib, agente antitumoral que inhibe selectivamente múltiples receptores de la tirosina cinasa). La paciente presentó mala evolución clínica con picos febriles y anemia severa refractarios a tratamiento, siendo exitus en 18 meses.

El carcinoma de células renales (CCR) es uno de los tumores urológicos más agresivos y representa el 3\% de las neoplasias del adulto, siendo el tercer tumor en frecuencia de los tumores del aparato genitourinario ${ }^{1}$. La tríada clásica de hematuria, dolor lumbar y masa palpable ocurre apenas en el 5-15\% de los casos $^{2}$. El 30\% de los enfermos con CCR tiene metástasis en el momento del diagnóstico, siendo su asiento más frecuente el pulmón (70\%), los ganglios linfáticos $(55 \%)$, el hueso (42\%), el hígado (41\%), las suprarrenales (15\%) y el SNC $(11 \%)^{1,3}$.

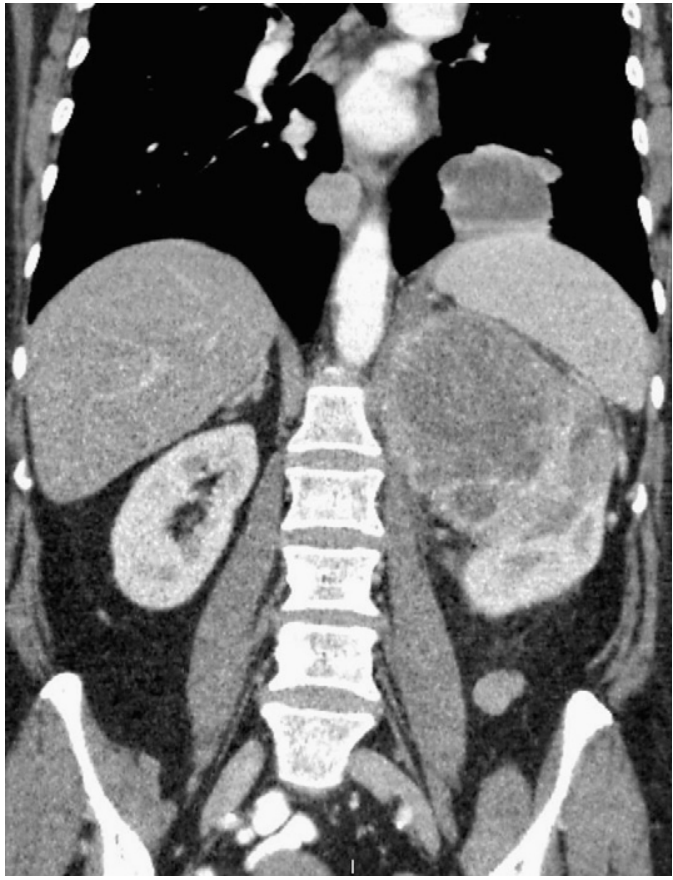

Figura 2 - Tomografía computarizada toracoabdominal que muestra una masa de $10 \mathrm{~cm}$ en el polo superior del riñón izquierdo y múltiples nódulos metastásicos pulmonares y retroperitoneales.

La afectación mamaria procedente de una tumoración maligna es extremadamente rara. Trevisthick en 1903 fue el primero en comunicar un linfoma de alto grado metastático en mama ${ }^{4}$; desde entonces se han publicado 400 casos en la literatura médica. La incidencia de metástasis de tumor primario extramamario en la mama oscila entre el 0,5-2\% Las neoplasias primitivas que más frecuentemente producen metástasis en la mama son melanoma, linfoma y leucemia ${ }^{6}$.

Las metástasis en la mama de CCR son excepcionales; sólo se han descrito 14 casos de metástasis en la mama, 7 casos como primera manifestación ${ }^{6}$.

Las metástasis en la mama simulan en la exploración clínica un cáncer de mama, siendo la información clínica y la histopatología claves para clarificar el caso.

En la mamografía, las lesiones se presentan como lesiones bien definidas sin calcificaciones, mientras que los tumores primarios suelen presentar espiculación y/o microcalcificación. Ambas mamas se afectan por igual y suelen tener un crecimiento más rápido. No suelen afectar a los ductos, producir retracción del pezón ni cambios en la piel. La afectación linfática axilar es variable ${ }^{6,7}$.

El diagnóstico de metástasis extramamaria es crucial para evitar mastectomía innecesaria y establecer el tratamiento de la neoplasia primaria ${ }^{7}$.

El pronóstico de los pacientes con carcinoma renal metastásico no tratado es infausto, con una supervivencia media del $5 \%$ a los 3 años ${ }^{8}$.

Para el CCR diseminado carecemos de opciones terapéuticas eficaces para la enfermedad diseminada ${ }^{9}$. El tratamiento de las metástasis es complejo por la gran quimiorresistencia y radiorresistencia que presentan. El tratamiento de elección es 
el quirúrgico, con la extirpación completa de la lesión, siempre que sea posible, sin que conlleve el sacrificio de estructuras vitales, las condiciones clínicas del paciente lo permitan y no existan desórdenes sistémicos ${ }^{10}$. Hoy en día se está extendiendo el uso del interferón $\alpha$ solo o acompañado de otros inmunomoduladores, como interleukina-2, fluoruracilo o ácido 13 cisretinoico, obteniéndose respuestas en un rango del $13-20 \%{ }^{6,8}$.

B I B L I O G R A F Í A

1. Wahner-Roedler DL, Sebo TJ. Renal cell carcinoma: Diagnosis based on metastatic manifestations. Mayo Clin Proc. 1997;72:935-41.

2. Calleja Escudero J, Pacual Samaniego M, Martin Blanco S, De Castro Olmedo C, Gonzalo V, Fernández del Busto E. Metástasis intraescrotal de un carcinoma renal. Actas Urol Esp. 2008:653-5.

3. Tarraza Jr HM, Meltzer SE, De Cain M, Jones MA. Vaginal metastases from renal cell carcinoma: Report of four cases and review of the literature. Eur J Gynaecol Oncol. 1998;19: 14-8.

4. Hajdn SI, Urban JA. Cancers metastatic to the breast. Cancer. 1972;29:1691-6.

5. Vassalli L, Ferrari VD, Simoncini E, Rangoni G, Montini E, Marpicati P, et al. Solitary breast metastases from a renal cell carcinoma. Breast Cancer Res Treat. 2001;68:29-31.
6. McLauglin S, Thiel D, Smith S, Wehle M, Menke D. Solitary breast mass as initial presentation of clinically silent metastatic renal cell carcinoma. The Breast. 15: 426-428.

7. Saenz de Santamaría Morales FJ, Campors de Orellana Gómez AM, Sánchez Chapado M, Cabezas Zamora M. Carcinoma renal metastásico en mama. Presentación de dos casos diagnosticados por citología mediante punción aspiración con aguja fina (PAAF). Arch Esp De Uro. 1990;43:75-7.

8. Torres Muros B, Solano Romero JR, Rodríguez Baró JG, Bonilla Parrilla R. Adenocarcinoma renal metastásico en seno maxilar. Actas Urol Esp. 2006;30:954-7.

9. García Torrelles M, Beltrán Armada JR, Verges prosper A, Santlaya García JI, Espinosa Ruiz JJ, Tarín Planes M, et al. Metástasis cutánea de células renales. Actas Urol Esp. 2007; 31:556-8.

10. Montoro Martínez V, López Vilas M, Gurri Freixa M, De Dios Oran E, Montserrat Gili JR, Fabra Llopis JM. Metástasis nasal de carcinoma renal. A propósito de un caso. Acta Otorrinolaringol Esp. 1999;50:653-6.

A. Mesa Álvarez*, A. Díaz García, E. Nava Tomás y J. Calvo Blanco

Servicio de Radiodiagnóstico, Hospital Universitario Central de Asturias, Oviedo, España

*Autor para correspondencia.

Correo electrónico: alimesa76@hotmail.com

(A. Mesa Álvarez).

\section{Metástasis uretral de origen colónico 14 meses después de la cistoprostatosigmoidectomía}

\section{Urethral metastasis from a colon carcinoma 14 months alter cystoprostatectomy and sigmoidectomy}

\section{Sr. Director}

En marzo de 2006, un varón de 71 años fue sometido a una cistoprostatosigmoidectomía por un cáncer de sigma que invadía la cúpula vesical. El diagnóstico anatomopatológico fue un adenocarcinoma de origen colónico, estadio T4NOMO. La próstata no estaba afectada y el antígeno carcinoembrionario estaba en su rango normal. Posteriormente se le aplicaron 5 ciclos de quimioterapia con oxaliplatino y 5 fluoruracilo complementados con radioterapia locorregional a dosis de 50 Gy.

Catorce meses más tarde, el paciente se quejó de la expulsión de una pequeña cantidad de líquido sanguinolento a través del meato uretral. Se realizó una citología, que fue positiva para adenocarcinoma, y una uretroscopia, que reveló una lesión polipoidea que bloqueaba casi completamente la luz de la uretra bulbar. Dicha lesión fue biopsiada, con el diagnóstico histológico de adenocarcinoma de colon moderadamente diferenciado, compatible con metástasis. El estudio de extensión se completó con una resonancia magnética pelviana, donde se objetivó una lesión de aspecto tumoral desde el muñón uretral hasta la uretra bulbar, y la ausencia de otras metástasis. La radiografía de tórax también fue negativa.

Con el diagnóstico de metástasis uretral única, realizamos una uretrectomía parcial vía perineal respetando la uretra a nivel del glande. El estudio macroscópico de la pieza mostró una lesión polipoide de $20 \times 7 \mathrm{~mm}$ en el interior de la uretra, cuyo análisis histológico confirmó el origen colónico de la lesión (fig. 1). Los márgenes quirúrgicos fueron negativos.

Seis meses más tarde, el paciente refirió la presencia de una masa exofítica que asomaba por el meato uretral externo 